\title{
Erratum to: Model Checking After Bayesian Inference
}

\author{
Matteo Pozzi and Daniele Zonta
}

\section{Erratum to:}

Chapter "Model Checking After Bayesian Inference" in:

P. Gardoni (ed.), Risk and Reliability Analysis: Theory

and Applications, Springer Series in Reliability Engineering, https://doi.org/10.1007/978-3-319-52425-2_14

The original version of the book was inadvertently published with the incorrect affiliation "Pittsburgh, UK", which has been now corrected as "Pittsburgh, USA" for author "Matteo Pozzi" in chapter "Model Checking After Bayesian Inference".

The updated online version of this chapter can be found at

https://doi.org/10.1007/978-3-319-52425-2_14 